\title{
Effects of endotoxemia on the pharmacodynamics and pharmacokinetics of ketamine and xylazine anesthesia in Sprague-Dawley rats
}

This article was published in the following Dove Press journal:

Veterinary Medicine: Research and Reports

4 October 2012

Number of times this article has been viewed

\author{
Daphnée Veilleux-Lemieux ${ }^{1,2}$ \\ Francis Beaudry' \\ Pierre Hélie ${ }^{3}$ \\ Pascal Vachon' \\ 'Department of Veterinary \\ Biomedicine, University of Montreal, \\ Saint-Hyacinthe, ${ }^{2}$ Department of \\ Veterinary Services, Laval University, \\ Quebec, ${ }^{3}$ Department of Pathology \\ and Microbiology, University of \\ Montreal, Saint-Hyacinthe, Canada
}

\begin{abstract}
Purpose: To evaluate the effects of endotoxemia on the pharmacokinetics and pharmacodynamics of ketamine and xylazine anesthesia in Sprague-Dawley rats.
\end{abstract}

Methods: Sprague-Dawley rats received ketamine $(80 \mathrm{mg} / \mathrm{kg})$ and xylazine $(5 \mathrm{mg} / \mathrm{kg})$ intramuscularly following the intraperitoneal administration of different lipopolysaccharide concentrations $(1,10$, and $100 \mu \mathrm{g} / \mathrm{kg})$ to simulate different levels of endotoxemia. Results were compared to control animals receiving saline intraperitoneally. During anesthesia, a toe pinch was performed to evaluate anesthesia duration, and selected physiological parameters (heart and respiratory rates, oxygen saturation, and rectal temperature) were taken. Blood samples were also taken during anesthesia at selected time points for the analysis of plasmatic ketamine and xylazine concentrations by liquid chromatography-mass spectrometry. Blood samples were taken 1 week prior to and 24 hours following anesthesia for blood biochemistry

Results: Anesthesia duration significantly increased for moderate $(10 \mu \mathrm{g} / \mathrm{kg})$ and high $(100 \mu \mathrm{g} / \mathrm{kg})$ lipopolysaccharide groups. Liver histopathology showed minor to moderate necrosis in all lipopolysaccharide groups in some animals. The most important physiological change that occurred was a decrease in oxygen saturation, and for blood biochemistry a decrease in serum albumin. Ketamine pharmacokinetics were not affected except for the moderate $(10 \mu \mathrm{g} / \mathrm{kg})$ lipopolysaccharide group where a decrease in the area under the plasma concentration-time curve from time zero to the last measurable concentration, a decrease in half-life, and an increase in the clearance were observed. For xylazine, the area under the plasma concentration-time curve increased and the clearance decreased in the moderate $(10 \mu \mathrm{g} / \mathrm{kg})$ and high $(100 \mu \mathrm{g} / \mathrm{kg})$ lipopolysaccharide groups.

Conclusion: During ketamine-xylazine anesthesia, endotoxemia may alter xylazine pharmacokinetics and selected biochemical and physiological parameters, suggesting that anesthetic drug dosages could be modified for a more rapid recovery.

Keywords: lipopolysaccharide, ketamine, xylazine, pharmacokinetics, rats

\section{Introduction}

Fever is a common clinical sign caused by endogenous or exogenous pyrogens and it is often associated with bacterial and viral infections. Lipopolysaccharides (LPS) are constituents of the bacterial cell wall that induces fever in animals. ${ }^{1}$ This exogenous pyrogen, which is a component of Gram-negative bacteria membranes, indirectly stimulates the production of inflammatory cytokines such as tumor necrosis factor- $\alpha$, interleukins, and interferons, which are endogenous pyrogens. ${ }^{2,3}$ These cytokines induce important functional modifications that affect different organs including the liver and the kidney. ${ }^{4,5}$ Pyrogens may decrease the metabolism of drugs by their action on liver
Correspondence: P Vachon Universite de Montreal, Faculte de Medecine Veterinaire, Departement de Biomedecine Veterinaire, 3200 Sicotte, Saint-Hyacinthe, Quebec H2L 2M2, Canada

$\mathrm{Tel}+\mid 450773852$ I ext 8294

Fax +l 4507788103

Email pascal.vachon@umontreal.ca 
cytochrome $\mathrm{P} 450$ in all animal species including rats. ${ }^{6,7}$ Renal excretion can also be altered since glomerular filtration rate and plasmatic renal flow are both reduced following pyrogen administration. ${ }^{8}$ Since endotoxemia may cause a decrease in liver metabolism and renal filtration, plasmatic concentrations of drugs could be altered with diseases or infections. ${ }^{3}$

Both xylazine - an $\alpha_{2}$-agonist that reduces noradrenergic activity in the brain and has sedative and antinociceptive properties - and ketamine - an N-methyl-D-aspartate antagonist that has a generalized depressant effect in all parts of the central nervous system, which explains its anesthetic properties - are used in combination to anesthetize rodents. ${ }^{9}$ The combination of xylazine and ketamine is often considered as a first choice of injectable anesthetics. ${ }^{10-12}$ They are rapidly absorbed after an intramuscular injection and well distributed to the central nervous system. ${ }^{13}$ Both are metabolized by the liver and excreted mainly by the kidney. ${ }^{10}$ However, little is known about the effects of endotoxins on the metabolism and excretion of these drugs.

The main objective of this study was to evaluate the pharmacokinetics and physiological changes associated with the administration of ketamine and xylazine in rats when administered at an anesthetic dose following the administration of different LPS concentrations. Previous experiments have used various LPS concentrations to induce fever. ${ }^{14-16}$ Hansen et al showed that an intraperitoneal injection of LPS $(1,10$, and $50 \mu \mathrm{g} / \mathrm{kg})$ induced fever in adult male SpragueDawley rats. ${ }^{1}$ Low $(1 \mu \mathrm{g} / \mathrm{kg})$, moderate $(10 \mu \mathrm{g} / \mathrm{kg})$, and high $(100 \mu \mathrm{g} / \mathrm{kg})$ doses of LPS were used to observe if there was a dose-effect relationship between endotoxemia and the pharmacological and physiological responses of ketaminexylazine anesthesia.

\section{Materials and methods} Animals and husbandry

Twenty-four male Sprague-Dawley rats (Charles River Laboratories, Saint-Constant, Canada) weighing between 300-350 g (approximately 8-9 weeks of age) were used for this study. After their arrival, animals were allowed 7 days of acclimation before the start of the experiments. They were housed in a standard laboratory animal environment (fresh filtered air, 15 changes/hour; temperature, $22^{\circ} \mathrm{C}-24^{\circ} \mathrm{C}$; humidity, 40\%-60\%; and light-dark cycle, 12:12 hours). The rats were group-housed (two rats/cage) in polycarbonate cages (Ancare, Bellmore, NY) on hardwood bedding (7090C Teklad Certified Sani-Chips; Harlan Laboratories, Madison, WI). They received tap water and a certified laboratory diet (2018 Teklad Global Rodent Diet ${ }^{\circledR}$; Harlan Laboratories) ad libitum. The experimental protocol was approved by the Laval University Institutional Animal Care and Use Committee (Quebec, Canada) prior to animal use, in accordance with the guidelines of the Canadian Council on Animal Care (Ottawa, Canada).

\section{Treatments}

The control group ( $\mathrm{n}=6$ rats) received $0.1 \mathrm{~mL}$ of pyrogenfree saline intraperitoneally ( $0.9 \%$ sodium chloride; Hospira, Inc, Lake Forest, IL) and each experimental group ( $\mathrm{n}=6$ rats/LPS concentration) received a $0.1 \mathrm{~mL}$ intraperitoneal injection of either 1,10 , or $100 \mu \mathrm{g} / \mathrm{kg}$ of LPS to simulate three levels of endotoxemia. ${ }^{1}$ LPS (Escherichia coli 011:B4; Sigma-Aldrich, St Louis, MO) and sterile saline were injected 2 hours prior to the ketamine-xylazine injection. LPS was dissolved in sterile pyrogen-free saline (Hospira) at an ambient temperature $\left(22^{\circ} \mathrm{C}-24^{\circ} \mathrm{C}\right)$. Ketamine $(80 \mathrm{mg} / \mathrm{kg}$; Ketalean; Bimeda-MTC, Cambridge, Canada) and xylazine (5 mg/kg; Xylamax; Bimeda-MTC) were administered intramuscularly in the hip extensor (semitendinosus and semimembranosus muscles).

\section{Evaluation of physiological parameters and the withdrawal reflex}

Baseline physiological measures and paw withdrawal response were taken 30 minutes before LPS administration. Prior to each blood collection (approximately 1 minute), body temperature, cardiac and respiratory frequencies, and blood oxygen saturation data were collected. Rectal temperature was monitored (TH-8 Thermalert; Physitemp Instruments, Inc, Clifton, NJ) and a small animal oximeter (8500 Handheld Pulse Oximeter; Nonin Medical, Inc, Plymouth, MN) was used for cardiac frequency and blood oxygen saturation monitoring. Respiratory frequency was monitored by direct observation and the withdrawal reflex was monitored by the reaction to a toe pinch. The toe pinch was performed by pressing the interdigital hind paw skin with hemostatic forceps prior to anesthesia and starting at 15 minutes after ketamine-xylazine administration continuing at each blood collection time point until a positive reaction (hind leg movement) was noted.

\section{Blood biochemistry and histological preparations}

Under isoflurane anesthesia, blood $(1 \mathrm{~mL})$ was collected from the jugular vein of each rat 1 week prior to and 24 hours after the ketamine-xylazine injection. It was placed in $1 \mathrm{~mL}$ serum tubes (Becton Dickinson, and Company, Franklin Lakes, NJ) 
for the evaluation of selected biochemical parameters with a Synchron CX ${ }^{\circledR} 5$ Pro Clinical System (Beckman Coulter, Brea, CA). Parameters included glucose, blood urea nitrogen, creatinine, alanine aminotransferase, alkaline phosphatase, total protein, albumin, and globulins. Experimental values were compared with normal ranges taken from published findings. ${ }^{17}$

Following euthanasia, the kidney and liver were collected and preserved in a buffered $10 \%$ formalin solution prior to histological preparations (staining with hematoxylin-eosin-saffron). Specimens were sent to the pathology department of the Faculty of Veterinary Medicine of the University of Montreal (Saint-Hyacinthe, Canada).

\section{Blood sampling for the pharmacokinetic study and urine collections}

Following ketamine-xylazine administrations, the animals were housed in rat metabolic cages (Tecniplast SpA, Buguggiate, Italy) for urine collection over 24 hours to evaluate total urinary volume and renal excretion of ketamine and xylazine. The excretion of both drugs is reported as the excreted fraction (ie, the total drug excreted - total drug administered). The total drug excreted was calculated from the urine concentration measured by high performance liquid chromatography (HPLC; Series 200; PerkinElmer, Waltham, MA), tandem mass spectrometer (Applied Biosystems/MDS Sciex PE Sciex API III+; Life Technologies, Carlsbad, CA) and total urinary output over 24 hours.

Prior to each jugular vein blood collection, animals were placed on a circulating hot water blanket. Blood samples ( $0.3 \mathrm{~mL} /$ time points) for the pharmacokinetic study were collected under isoflurane anesthesia $(0.5 \mathrm{~L} /$ minute oxygen $)$, with the use of a mask, at 5, 15, and 30 minutes and 1, 2, 6 , and 24 hours after ketamine-xylazine administration. The total time for each blood collection was approximately 1 minute. Blood was collected in $1 \mathrm{~mL}$ BD Microtainer ${ }^{\circledR}$ tubes with potassium ethylenediaminetetraacetic acid (Becton Dickinson). Samples were maintained on ice and centrifuged (3200 g for 10 minutes) within 30 minutes of collection. Immediately following the last blood collection, the rats were euthanized by isoflurane overdose. All samples were kept at $-80^{\circ} \mathrm{C}$ pending analysis by HPLC tandem mass spectrometer.

\section{Bioanalytical method}

The analysis of ketamine and xylazine was performed using an HPLC tandem mass spectrometer. Ketamine and xylazine were extracted from rat plasma using a protein precipitation method. Each plasma sample $(50 \mu \mathrm{L})$ was mixed with $250 \mu \mathrm{L}$ of internal standard solution $(100 \mathrm{ng} / \mathrm{mL}$ of dextromethorphan in an acetone/methanol ratio of 50:50) in a $1.5 \mathrm{~mL}$ centrifuge tube. For the urine samples, $50 \mu \mathrm{L}$ of urine was mixed with $1 \mathrm{~mL}$ of the internal standard solution. Samples were vortexed, allowed to rest 10 minutes, and then centrifuged (12,000 $\mathrm{g}$ for 10 minutes). Using an isocratic mobile phase with a Hypersil Phenyl $100 \times 2 \mathrm{~mm}$ column (Thermo Fisher Scientific, Waltham, MA), $200 \mu \mathrm{L}$ of the supernatant was used for chromatographic separation. The mobile phase consisted of acetonitrile, methanol, and $0.5 \%$ formic acid in water at a ratio of 60:20:20, respectively, with a fixed flow rate of $0.3 \mathrm{~mL} /$ minute; $2 \mu \mathrm{L}$ of the extracted sample was injected and the total run time was set to 3 minutes. The mass spectrometer was interfaced with the HPLC system using a pneumatic assisted electrospray ion source. The nitrogen pressure of the nebulizer gas was set at $40 \mathrm{psi}$ and the electrospray ionization electrode was set to $4000 \mathrm{~V}$. The declaustering potential was set at $15 \mathrm{~V}$ and the laboratory collision energy at $22.5 \mathrm{~V}$. The collision gas used was argon. The selected reaction monitoring transitions were $\mathrm{m} / \mathrm{z} 238 \rightarrow 163,221 \rightarrow 90$, and $272 \rightarrow 215$ for ketamine, xylazine, and dextromethorphan, respectively. The analytical ranges used were $0.1-25 \mu \mathrm{g} / \mathrm{mL}$ for ketamine and $0.01-5.0 \mu \mathrm{g} / \mathrm{mL}$ for xylazine. Observed coefficients of determination were $\geq 0.9987$ and $\geq 0.9976$ for ketamine and xylazine, respectively. The precisions obtained ranged from $2.3 \%-9.2 \%$ and $1.5 \%-6.9 \%$ for ketamine and xylazine, respectively. Likewise, the accuracy observed was $96.9 \%-100.5 \%$ and $92.2 \%-111.7 \%$ for ketamine and xylazine, respectively. The lower limit of quantitation was set at $0.1 \mu \mathrm{g} / \mathrm{mL}$ and $0.01 \mu \mathrm{g} / \mathrm{mL}$ for ketamine and xylazine, respectively.

\section{Pharmacokinetics}

Pharmacokinetic parameters of ketamine and xylazine in plasma were calculated using noncompartmental methods. ${ }^{18}$ The area under the curve from time zero to the last measurable concentration $\left(\mathrm{AUC}_{0-\mathrm{t}}\right)$ was calculated using the linear trapezoidal rule. A terminal rate constant of elimination was calculated using a minimum of three measurable plasma concentrations and a terminal elimination half-life was calculated using 0.693/kel. All parameters were confirmed by using a one-compartment model using Pharsight ${ }^{\circledR}$ WinNonlin ${ }^{\circledR}$ version 5.3 (Certara, St Louis, MO). The correlation between fitted and observed concentrations for ketamine and xylazine was 0.9840 and 0.9869 , respectively. Reported pharmacokinetic values are from WinNonlin. 


\section{Statistical analyses}

Duration of the ketamine-xylazine anesthesia was evaluated using a chi-squared statistical test with a priori contracts to see if there were differences when comparing LPS groups to controls. All hematologic and biochemistry data were analyzed statistically by using $t$-tests. Pre-post anesthesia values were compared for all groups. Parametric repeated measures analysis of variance and Tukey's post hoc analysis were used for physiologic and pharmacologic data. Statistical significance was set at $P<0.05$.

\section{Results}

Prior to the ketamine-xylazine administration, rats receiving $1 \mu \mathrm{g} / \mathrm{kg}$ of LPS appeared normal. Rats receiving $10 \mu \mathrm{g} / \mathrm{kg}$ were slightly amorphous, showing decreased exploratory movement in the cage compared to the controls and the $1 \mu \mathrm{g} / \mathrm{kg}$ LPS group; however, a slightly hunched posture with piloerection and a clear decrease of spontaneous movement was apparent with $100 \mu \mathrm{g} / \mathrm{kg}$.

\section{Anesthesia duration}

Anesthesia duration, demonstrated by the percentage of Sprague-Dawley rats showing a positive hind paw pinch reaction, following ketamine-xylazine administration is presented in Figure 1. The toe pinch reflex was absent in these animals at 5 minutes and 15 minutes; however, at the 30-minute time point, animals receiving $1 \mathrm{mg} / \mathrm{kg}$ LPS were still anesthetized $(P<0.05)$ when compared to controls. In these animals, the withdrawal reflex was again present 1 hour following ketamine-xylazine administration. All animals that received $10 \mu \mathrm{g} / \mathrm{kg}$ or $100 \mu \mathrm{g} / \mathrm{kg}$ of LPS had a toe pinch reflex 2 hours after ketamine-xylazine injection, but these groups were statistically different from the controls at 1 hour $(P<0.01$ and $P<0.05$, respectively), as most animals were still anesthetized at this time point. Therefore, the control animals and animals receiving the low LPS concentration had a shorter anesthesia duration than animals receiving the moderate and high LPS concentrations.

\section{Physiological changes}

Rectal temperature was significantly lower with $1 \mu \mathrm{g} / \mathrm{kg}$ LPS at 2 hours and 6 hours $(P<0.0001)$ and at 2 hours with $10 \mu \mathrm{g} / \mathrm{kg}$ LPS $(P<0.05)$ in comparison to the controls (Figure 2). No significant difference was found with the $100 \mu \mathrm{g} / \mathrm{kg}$ LPS administration.

No changes in respiratory frequency occurred with different LPS administrations except at 6 hours when all LPS groups showed a lower respiratory frequency in comparison to the controls $(P<0.05)$ (Figure 3$)$.

The effects of LPS during anesthesia on cardiac frequency are presented in Figure 4. The high LPS group had a higher

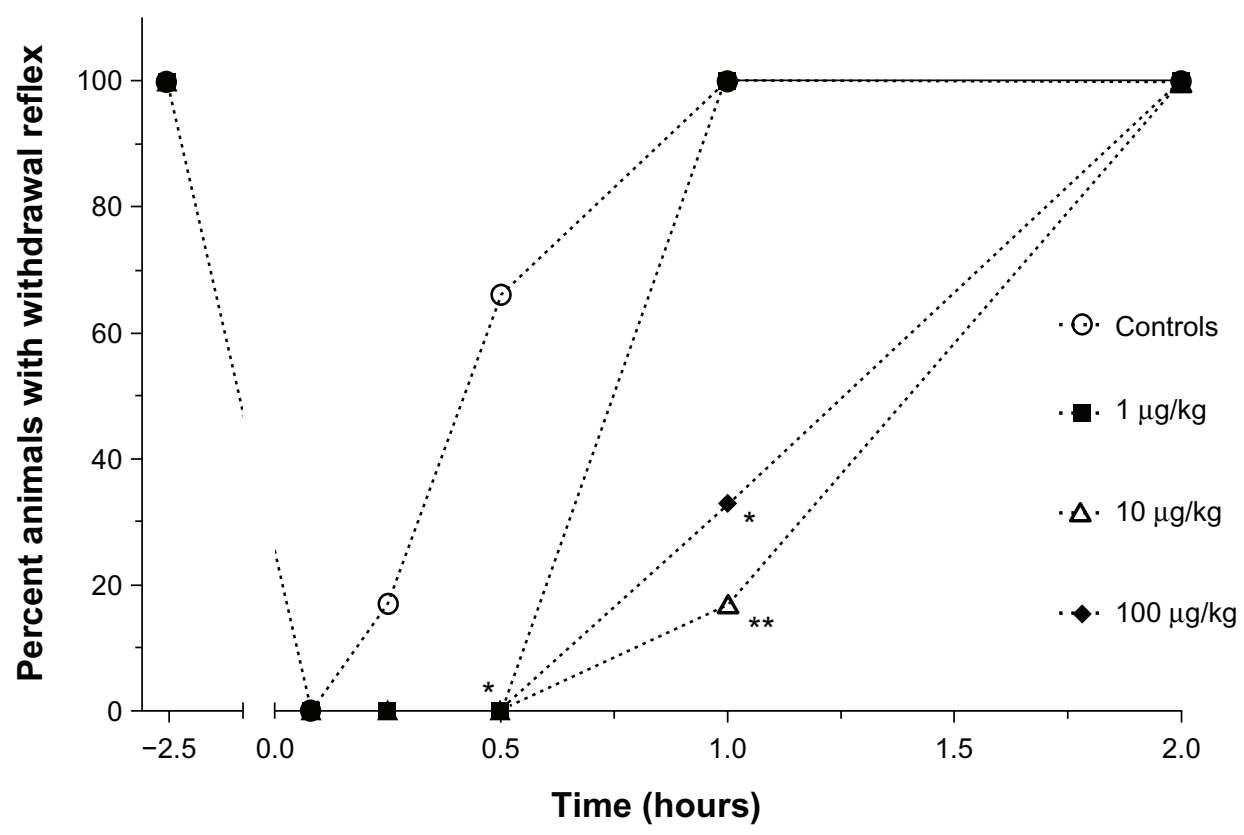

Figure I Percentage of Sprague-Dawley rats $(n=6 /$ group) showing a positive hind paw pinch reaction 30 minutes prior to lipopolysaccharide administrations $(2.5$ hours prior to the administration of anesthetics) and starting at 15 minutes after administration of ketamine and xylazine continuing at each blood collection time point (5, I5, and 30 minutes and I, 2, 6, and 24 hours).

Note: Animals received either saline (controls) or different concentrations of Escherichia coli lipopolysaccharide (I, 10 , or I00 $\mu \mathrm{g} / \mathrm{kg})$ injected intraperitoneally $2 \mathrm{hours}$ before a ketamine $(80 \mathrm{mg} / \mathrm{kg})$ and xylazine $(5 \mathrm{mg} / \mathrm{kg})$ intramuscular injection. 


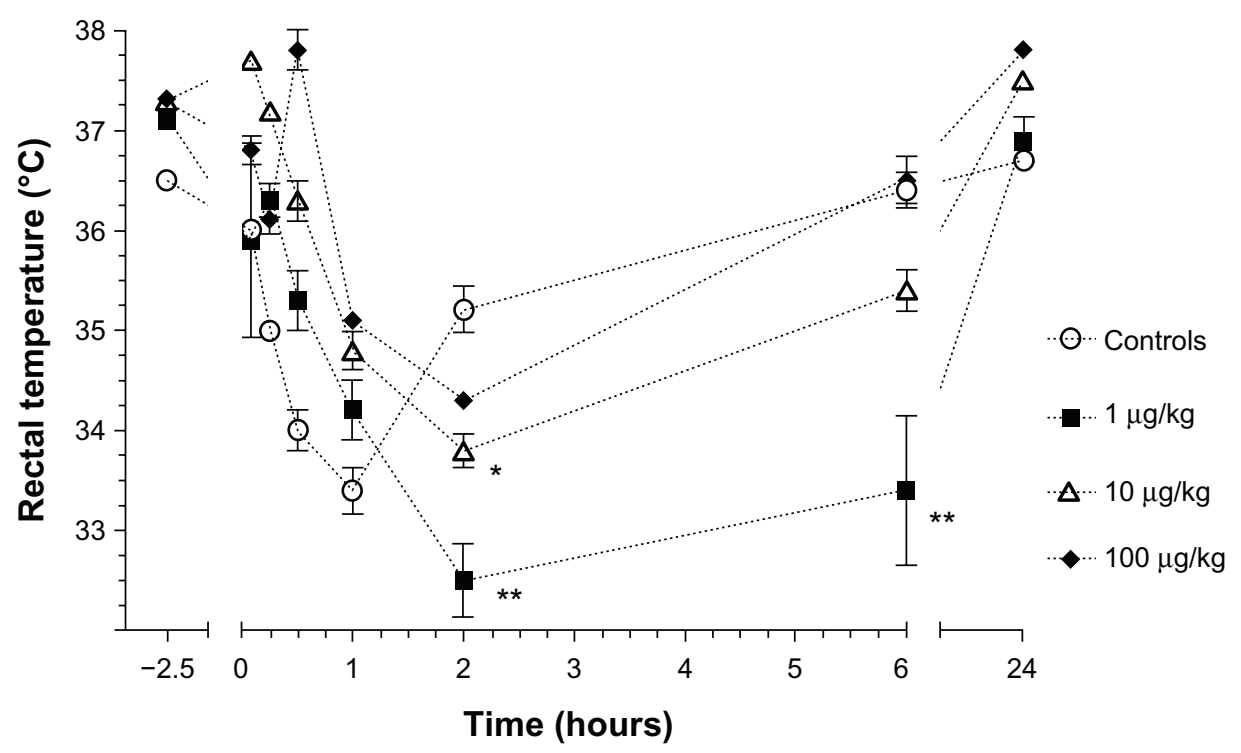

Figure 2 Mean ( \pm standard error) rectal temperature in Sprague-Dawley rats ( $n=6 /$ group) prior to polysaccharide administrations $(2.5$ hours prior to the administration of anesthetics) and following an intramuscular injection of ketamine $(80 \mathrm{mg} / \mathrm{kg})$ and xylazine $(5 \mathrm{mg} / \mathrm{kg})$ at 5,15 , and 30 minutes and I, 2, 6, and 24 hours in animals that received either saline (controls) or different concentrations of Escherichia coli lipopolysaccharide ( 1,10 , or $100 \mu g / k g)$ injected intraperitoneally 2 hours before anesthesia. Notes: $* P<0.05 ; * * P<0.0001$.

cardiac frequency at 1 hour and 2 hours $(P<0.0001)$, and at the 6-hour time point the $1 \mu \mathrm{g} / \mathrm{kg}(P<0.0001)$ and the $10 \mu \mathrm{g} / \mathrm{kg}(P<0.01)$ group had a lower cardiac frequency in comparison to the controls. At 24 hours following a $1 \mu \mathrm{g} / \mathrm{kg}$ LPS injection, the cardiac frequency was still lower than the controls $(P<0.01)$.

Blood oxygen saturation was significantly lower during the first 30 minutes for the low and moderate LPS groups $(P<0.0001)$, and less so at 1 hour $(P<0.05)$. The high
LPS group had an increased oxygen saturation at 5 minutes $(P<0.05)$ and decreased oxygen saturation at 15 minutes and 30 minutes $(P<0.05)$ when compared to the controls (Figure 5).

\section{Biochemical and pathological changes}

Biochemical results are presented in Table 1. All pre-post anesthesia values are within normal limits except for plasmatic albumin. The decrease of albumin with anesthesia

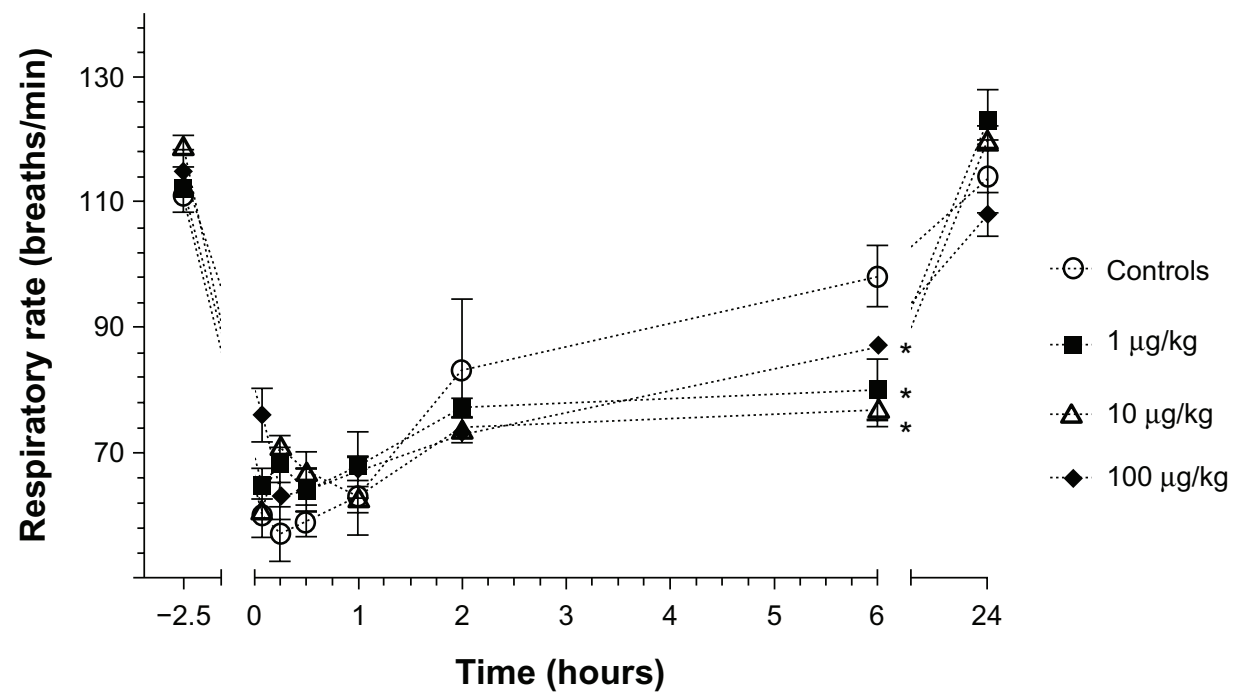

Figure 3 Mean ( \pm standard error) respiratory frequency in Sprague-Dawley rats ( $n=6 /$ group) prior to lipopolysaccharide administrations ( 2.5 hours prior to the administration of anesthetics) and following an intramuscular injection of ketamine $(80 \mathrm{mg} / \mathrm{kg})$ and xylazine $(5 \mathrm{mg} / \mathrm{kg})$ at 5,15 , and 30 minutes and I, 2, 6, and 24 hours in animals that received either saline (controls) or different concentrations of Escherichia coli lipopolysaccharide (I, I0, or $100 \mu \mathrm{g} / \mathrm{kg}$ ) injected intraperitoneally 2 hours before anesthesia. Note: $* p<0.05$ 


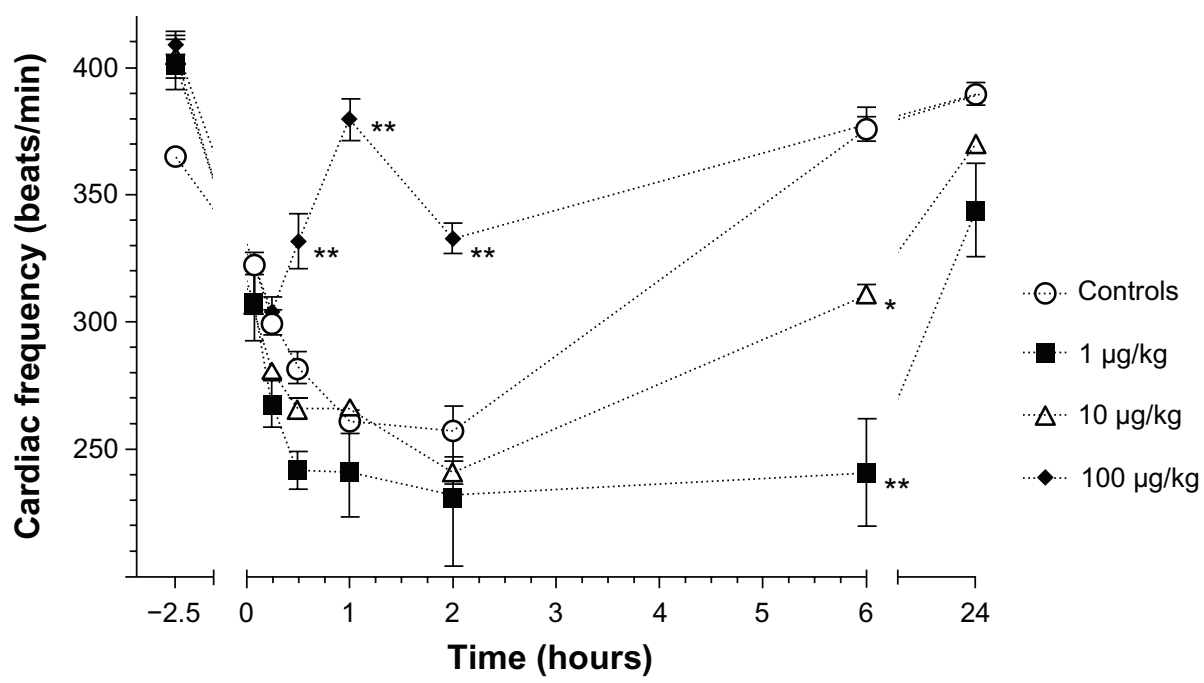

Figure 4 Mean ( \pm standard error) cardiac frequency in Sprague-Dawley rats $(n=6 / g r o u p)$ prior to lipopolysaccharide administrations ( 2.5 hours prior to the administration of anesthetics) and following an intramuscular injection of ketamine $(80 \mathrm{mg} / \mathrm{kg})$ and xylazine $(5 \mathrm{mg} / \mathrm{kg})$ at $5, \mathrm{I}$, and 30 minutes and I, 2, 6, and 24 hours in animals that received either saline (controls) or different concentrations of Escherichia coli lipopolysaccharide ( 1,10 , or $100 \mu g / k g)$ injected intraperitoneally 2 hours before anesthesia.

Notes: $* P<0.01 ; * * P<0.0001$.

for the $1 \mu \mathrm{g} / \mathrm{kg}$ and $10 \mu \mathrm{g} / \mathrm{kg}$ LPS concentrations was not significantly different from the saline controls; however, a more significant decrease in plasmatic albumin occurred for the $100 \mu \mathrm{g} / \mathrm{kg}$ LPS group $(P<0.01)$.

In all LPS groups, minor multifocal hepatic necrosis with the presence of neutrophils and macrophages were observed in two animals. In an additional two animals from the $100 \mu \mathrm{g} / \mathrm{kg}$ LPS group, a moderate multifocal hepatic necrosis with the presence of macrophages was observed. No lesions were seen in the kidneys in either control animals or animals that received different concentrations of LPS.

\section{Pharmacokinetics of ketamine and xylazine}

Mean concentration-time profiles of ketamine and xylazine are depicted in Figure 6. Mean pharmacokinetic parameters for ketamine are presented in Table 2. Pharmacokinetic parameters for ketamine were similar for all groups except for the $10 \mu \mathrm{g} / \mathrm{kg}$ LPS group where the $\mathrm{AUC}_{0-\mathrm{t}}$ significantly decreased $(P<0.0001)$ and the maximum plasma drug concentration occurred earlier $(P<0.0001)$. The half-life significantly decreased $(P<0.0001)$ and the clearance significantly increased $(P<0.0001)$.

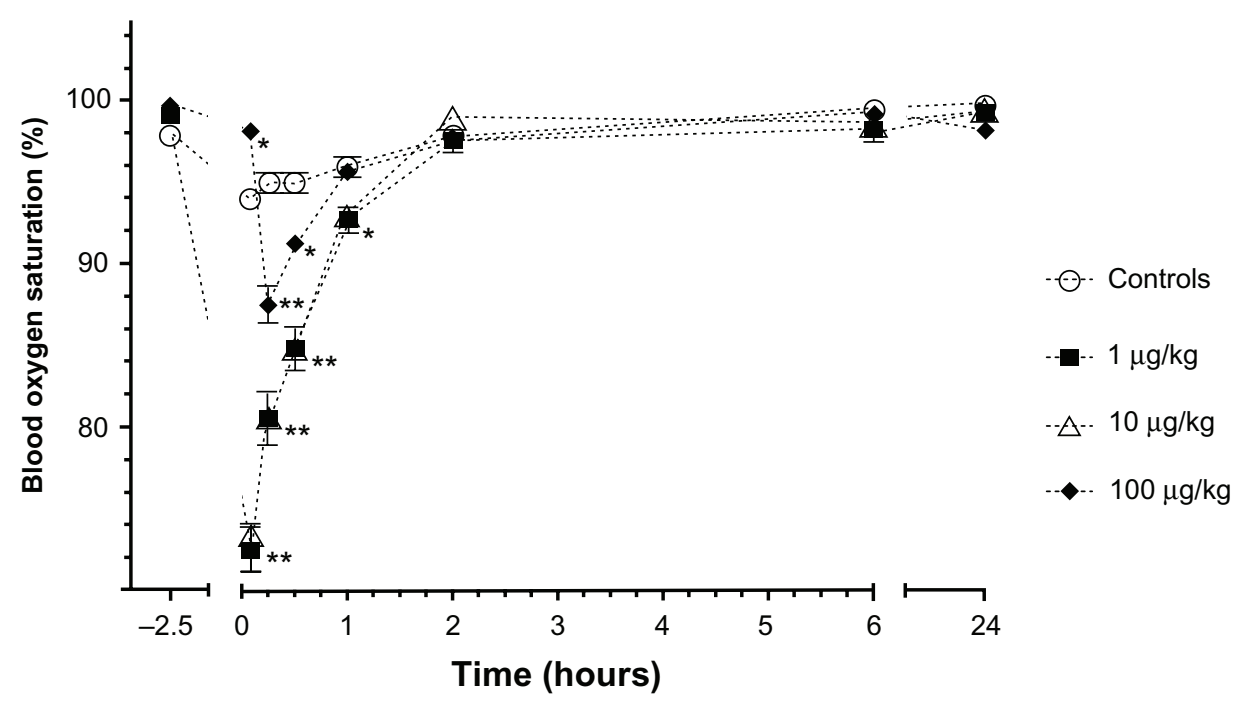

Figure 5 Mean ( \pm standard error) blood oxygen saturation in Sprague-Dawley rats ( $n=6 /$ group) prior to lipopolysaccharide administrations ( 2.5 hours prior to the administration of anesthetics) and following an intramuscular injection of ketamine $(80 \mathrm{mg} / \mathrm{kg})$ and xylazine $(5 \mathrm{mg} / \mathrm{kg})$ at 5,15 , and 30 minutes and I, 2, 6, and 24 hours in animals that received either saline (controls) or different concentrations of Escherichia coli lipopolysaccharide (I, I0, or $100 \mu \mathrm{g} / \mathrm{kg}$ ) injected intraperitoneally 2 hours before anesthesia. Notes: $* P<0.05$; **P $<0.0001$. 
Table I Mean ( \pm standard deviation) biochemical parameters in Sprague-Dawley rats ( $\mathrm{n}=6 /$ group) from a blood collection ( $\mathrm{I} \mathrm{mL})$ taken I week prior to and 24 hours after an intramuscular injection of ketamine $(80 \mathrm{mg} / \mathrm{kg})$ and xylazine $(5 \mathrm{mg} / \mathrm{kg})$ in controls (saline intraperitoneally) and in animals that received Escherichia coli lipopolysaccharide ( 1,10 , or $100 \mu g / k g$ intraperitoneally) injected 2 hours before anesthesia

\begin{tabular}{|c|c|c|c|c|c|c|c|c|c|}
\hline \multirow[t]{2}{*}{ Parameters } & \multirow{2}{*}{$\begin{array}{l}\text { Normal } \\
\text { values }\end{array}$} & \multicolumn{2}{|c|}{ Control group } & \multicolumn{2}{|c|}{ LPS I $\mu \mathrm{g} / \mathrm{kg}$} & \multicolumn{2}{|c|}{ LPS $10 \mu \mathrm{g} / \mathrm{kg}$} & \multicolumn{2}{|c|}{ LPS $100 \mu \mathrm{g} / \mathrm{kg}$} \\
\hline & & Before & After & Before & After & Before & After & Before & After \\
\hline Glucose (mmol/L) & $4.4-16.7$ & $10.2(1.58)$ & $4.3(3.22)$ & $8.6(0.50)$ & $8.8(1.13)$ & $10.2(1.04)$ & $8.8(1.23)$ & $8.2(0.65)$ & 9.1 (I.78) \\
\hline BUN (mmol/L) & $3.9-8.2$ & $5.39(0.47)$ & $5(0.77)$ & $5.19(0.54)$ & $4.20(1.56)$ & $5.06(0.32)$ & $4.04(0.48)$ & $4.8(0.32)$ & $8.28(6.24)$ \\
\hline Creatinine $(\mu \mathrm{mol} / \mathrm{L})$ & $35-123$ & $33(4.3)$ & $37(6.30)$ & $31(2.10)$ & $33(4.49)$ & $31(1.75)$ & $34.5^{* *}(3.02)$ & $28(1.03)$ & $34 *(5.18)$ \\
\hline ALT (U/L) & $28-40$ & $38(6.30)$ & $58(12.24)$ & $53(5.64)$ & $57(8.80)$ & $52(4.17)$ & $57(9.05)$ & $56(10.43)$ & $148(105.4)$ \\
\hline Total protein $(g / L)$ & $58-66$ & $53.5(4.19)$ & $51.3(2.74)$ & $55.0(2.72)$ & $48.3^{* *}(3.75)$ & $53.4(3.04)$ & $51.8(2.4 I)$ & $53.2(1.46)$ & $47.3 * *(1.95)$ \\
\hline Albumin $(\mathrm{g} / \mathrm{L})$ & $33-46$ & $31.6(1.13)$ & $28.3 * *(1.77)$ & $33.0(1.22)$ & $27.7 * *(1.58)$ & $31.8(0.98)$ & $28.0 * *(1.15)$ & $32.6(0.78)$ & $25.9 * *(0.89)$ \\
\hline Globulins (g/L) & $17-30$ & $21.9(3.22)$ & $23(1.93)$ & $22.0(1.60)$ & $20.6(2.33)$ & $21.7(2.24)$ & $23.8(1.60)$ & $20.6(0.82)$ & $21.5(1.35)$ \\
\hline
\end{tabular}

Notes: $* P \leq 0.05 ; * * P \leq 0.01$.

Abbreviations: ALT, alanine aminotransferase; BUN, blood urea nitrogen; LPS, lipopolysaccharide.
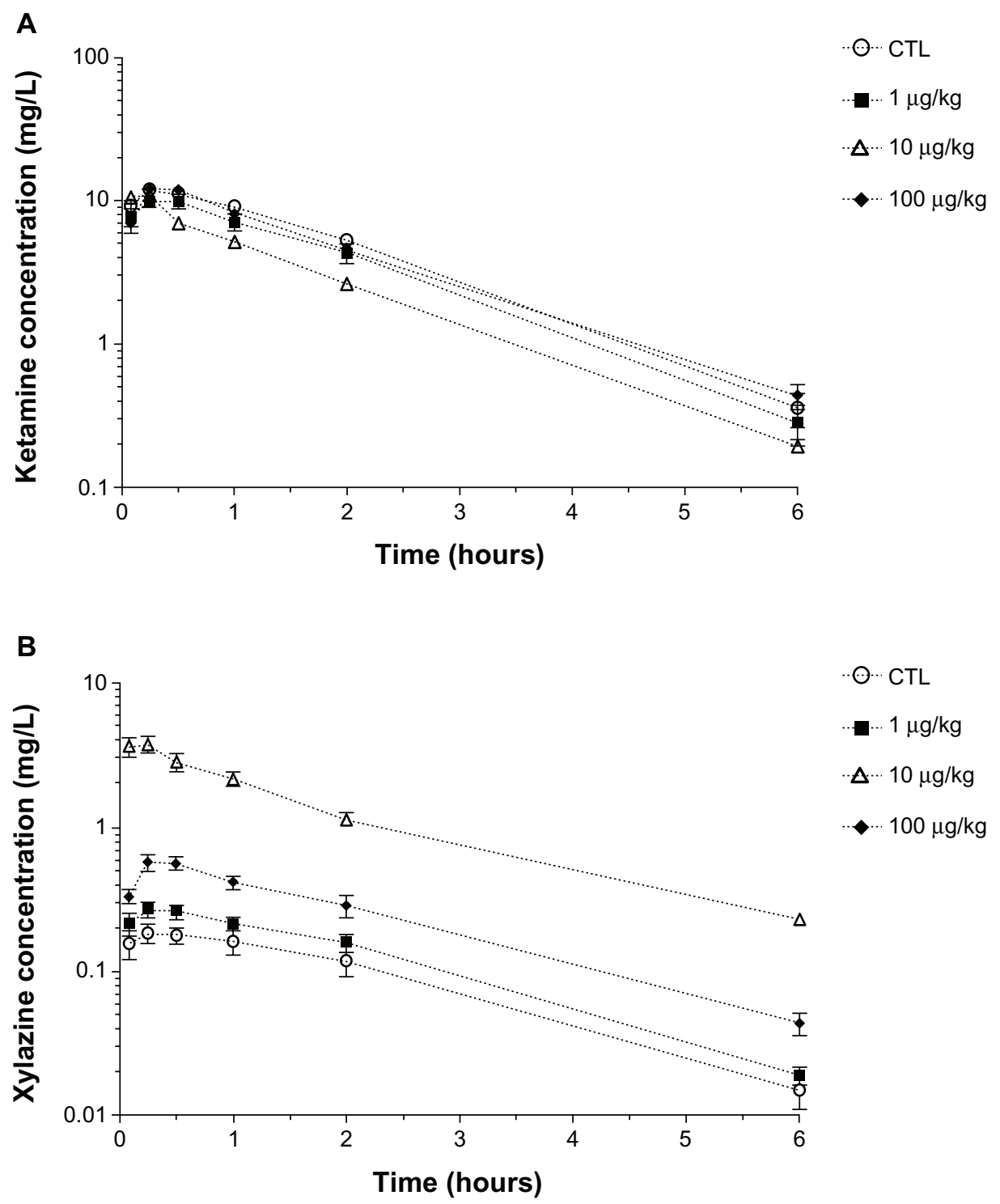

Figure 6 Mean ( \pm standard error) concentration-time profiles of (A) ketamine and (B) xylazine in plasma following an intramuscular administration of ketamine (80 $\mathrm{mg} / \mathrm{kg}$ ) and xylazine $(5 \mathrm{mg} / \mathrm{kg})$ in combination with an intraperitoneal administration of either saline (controls; $\mathrm{n}=6$ rats) or different concentrations of Escherichia coli lipopolysaccharide ( 1,10 , or $100 \mu g / k g ; n=6$ rats/lipopolysaccharide concentration) 2 hours before anesthesia. Abbreviation: CTL, controls. 
Table 2 Mean ( \pm standard error) pharmacokinetic parameters of ketamine for controls and lipopolysaccharide groups (SpragueDawley rats, $\mathrm{n}=6 /$ group) that received either saline (controls) or Escherichia coli lipopolysaccharide (I, 10, or $100 \mu g / \mathrm{kg})$ injected intraperitoneally 2 hours before an intramuscular injection of ketamine $(80 \mathrm{mg} / \mathrm{kg})$ and xylazine $(5 \mathrm{mg} / \mathrm{kg})$

\begin{tabular}{|c|c|c|c|c|}
\hline Parameters & Control & $\mathrm{I} \mu \mathrm{g} / \mathbf{k g}$ & $10 \mu \mathrm{g} / \mathrm{kg}$ & $100 \mu \mathrm{g} / \mathrm{kg}$ \\
\hline $\mathrm{AUC}_{0-\mathrm{t}}(\mathrm{mg}$-hour$/ \mathrm{L})$ & $25.82 \pm 1.88$ & $20.87 \pm 3.08$ & $15.35 \pm 0.77^{*}$ & $23.99 \pm 1.93$ \\
\hline CL/F (L/hour/kg) & $3.18 \pm 0.24$ & $4.22 \pm 0.52$ & $5.28 \pm 0.26 *$ & $3.44 \pm 0.28$ \\
\hline $\mathrm{T}_{1 / 2}$ (hours) & $1.20 \pm 0.05$ & $1.09 \pm 0.09$ & $0.88 \pm 0.02^{*}$ & $1.09 \pm 0.08$ \\
\hline $\mathrm{T}_{\max }$ (hours) & $0.27 \pm 0.03$ & $0.30 \pm 0.03$ & $0.14 \pm 0.02 *$ & $0.34 \pm 0.04$ \\
\hline $\mathrm{C}_{\max }(\mathrm{mg} / \mathrm{L})$ & $12.65 \pm 0.77$ & $10.58 \pm 1.16$ & $10.83 \pm 0.66$ & $12.40 \pm 1.05$ \\
\hline
\end{tabular}

Note: $* P \leq 0.0001$.

Abbreviations: $\mathrm{AUC}_{0-\mathrm{t}}$, area under the plasma concentration-time curve from time zero to the last measurable concentration; $\mathrm{CL} / \mathrm{F}$, total clearance of the drug after oral administration; $\mathrm{C}_{\text {max }}$, maximum plasma drug concentration; $\mathrm{T}_{1 / 2}$, half-life; $\mathrm{T}_{\text {max }}$, time taken to reach the maximum plasma drug concentration.

Mean pharmacokinetic parameters for xylazine are presented in Table 3. Mean pharmacokinetic parameters of xylazine of the $1 \mu \mathrm{g} / \mathrm{kg}$ LPS group were not significantly different from the control group. An increase in $\mathrm{AUC}_{0-\mathrm{t}}$ and maximum plasma concentration were seen for the $10 \mu \mathrm{g} / \mathrm{kg}$ and $100 \mu \mathrm{g} / \mathrm{kg}$ LPS groups $(P<0.0001)$. A decrease in xylazine clearance was also observed in both groups $(P<0.0001)$. These changes were more important for the group that received $10 \mu \mathrm{g} / \mathrm{kg}$ LPS in comparison to $100 \mu \mathrm{g} / \mathrm{kg}$ LPS.

Urinary volumes collected over 24 hours for the $1 \mu \mathrm{g} / \mathrm{kg}$ and $10 \mu \mathrm{g} / \mathrm{kg}$ LPS groups (mean $=16 \pm 7 \mathrm{~mL}$ ) did not differ significantly from the controls (mean $=12 \pm 3 \mathrm{~mL}$ ). However, the urinary output significantly increased following the administration of $100 \mu \mathrm{g} / \mathrm{kg}$ LPS (mean $=33 \pm 15 \mathrm{~mL} ; P<0.01$ ). The excreted fractions of ketamine and xylazine with different LPS administration are presented in Table 4. For ketamine, only the administration of $100 \mu \mathrm{g} / \mathrm{kg}$ LPS caused a significant increase in the excreted faction $(P<0.01)$. For xylazine, both the $10 \mu \mathrm{g} / \mathrm{kg}$ $(P<0.001)$ and $100 \mu \mathrm{g} / \mathrm{kg}(P<0.05)$ LPS administration caused an increase in the excreted urinary fraction.

\section{Discussion}

Increasing concentrations of LPS during ketamine-xylazine anesthesia in Sprague-Dawley rats caused significant pharmacokinetic, biochemical, and pathophysiological changes. Anesthesia duration increased; however, this cannot be explained by physiological changes. Increased duration could be related to other factors such as drug metabolism or the drug tissue availability, which may change with endotoxemia. To generalize the current findings, these studies should be done in rats of different gender, species, and age before they can be broadly applied to different experimental models.

In intact animals, LPS causes a release of endogenous pyrogens that produces fever, ${ }^{19}$ which increases metabolism and oxygen demand. A mainly hypothermic response was seen with LPS administration. Thermoregulatory responses to infection are well studied in the rat, and in both rats and humans, infection can induce febrile, hypothermic, or mixed hypothermic and febrile responses. ${ }^{20}$ The cardiovascular system responds by increasing heart rate and peripheral vasodilatation to increase skin blood flow, allowing heat dissipation. ${ }^{21}$ In the current experiment, LPS had little effect on early postanesthesia cardiac frequency except for the $100 \mu \mathrm{g} / \mathrm{kg}$ LPS dose, which caused an increase in heart rate. In many species, the ketamine-xylazine combination is known to decrease the heart rate. ${ }^{22-24}$ The current results suggest that this effect could only be overcome with high LPS concentration.

Table 3 Mean ( \pm standard error) pharmacokinetic parameters of xylazine for controls and lipopolysaccharide groups (SpragueDawley rats, $\mathrm{n}=6 /$ group) that received either saline (controls) or Escherichia coli lipopolysaccharide (I, 10 , or 100 $\mu \mathrm{g} / \mathrm{kg})$ injected intraperitoneally 2 hours before an intramuscular injection of ketamine $(80 \mathrm{mg} / \mathrm{kg})$ and xylazine $(5 \mathrm{mg} / \mathrm{kg})$

\begin{tabular}{|c|c|c|c|c|}
\hline Parameters & Saline & I $\mu \mathrm{g} / \mathrm{kg}$ & $10 \mu \mathrm{g} / \mathrm{kg}$ & $100 \mu \mathrm{g} / \mathrm{kg}$ \\
\hline $\mathrm{AUC}_{0-\mathrm{t}}(\mathrm{mg}$-hour/L) & $0.54 \pm 0.11$ & $0.74 \pm 0.09$ & $7.11 \pm 0.68 *$ & $1.44 \pm 0.2^{*}$ \\
\hline CL/F (L/hour/kg) & $10.99 \pm 2.38$ & $7.35 \pm 1.13$ & $0.74 \pm 0.09 *$ & $3.85 \pm 0.55^{*}$ \\
\hline$T_{1 / 2}$ (hours) & $1.59 \pm 0.13$ & $1.62 \pm 0.06$ & $1.34 \pm 0.11$ & $1.38 \pm 0.07$ \\
\hline $\mathrm{T}_{\max }$ (hours) & $0.27 \pm-0.03$ & $0.28 \pm 0.03$ & $0.19 \pm 0.02$ & $0.34 \pm 0.04$ \\
\hline $\mathrm{C}_{\max }(\mathrm{mg} / \mathrm{L})$ & $0.20 \pm 0.03$ & $0.28 \pm 0.04$ & $3.69 \pm 0.52 *$ & $0.58 \pm 0.06^{*}$ \\
\hline
\end{tabular}

Note: $* P \leq 0.0001$.

Abbreviations: $\mathrm{AUC}_{0-\mathrm{e}}$, area under the plasma concentration-time curve from time zero to the last measurable concentration; $\mathrm{CL} / \mathrm{F}$, total clearance of the drug after oral administration; $C_{\text {max }}$, maximum plasma drug concentration; $T_{1 / 2}$, half-life; $T_{\text {max }}$, time taken to reach the maximum plasma drug concentration. 
Table 4 Mean ( \pm standard error) fractional excretion of ketamine and xylazine following a 24-hour urine collection for control animals (saline intraperitoneally) and animals that received Escherichia coli lipopolysaccharide ( 1 , I0, or $100 \mu \mathrm{g} / \mathrm{kg}$ intraperitoneally) 2 hours before an intramuscular injection of ketamine $(80 \mathrm{mg} / \mathrm{kg})$ and xylazine $(5 \mathrm{mg} / \mathrm{kg})$

\begin{tabular}{llc}
\hline Groups & FE ketamine & FE xylazine \\
\hline Saline & $1.4 \pm 0.4$ & $0.6 \pm 0.1$ \\
$\mathrm{I} \mu \mathrm{g} / \mathrm{kg}$ & $1.9 \pm 0.2$ & $1.0 \pm 0.2$ \\
$10 \mu \mathrm{g} / \mathrm{kg}$ & $2.4 \pm 0.3$ & $16.1 \pm 2.9$ \\
$100 \mu \mathrm{g} / \mathrm{kg}$ & $3.8 \pm 0.5$ & $5.1 \pm 2.0$ \\
\hline
\end{tabular}

Abbreviation: $\mathrm{FE}$, fractional excretion.

Both ketamine and xylazine can cause a dose-dependent respiratory depression. ${ }^{25}$ However, xylazine in known to cause minimal effect on respiration. ${ }^{26}$ In the current experiment, a decrease in the respiratory rate that was observed following the administration of anesthetic drugs was not affected by LPS except at the 6-hour time point. Oxygen saturation was unchanged in the controls and decreased at the early time points for all LPS groups; the most important effect was seen with $1 \mu \mathrm{g} / \mathrm{kg}$ and $10 \mu \mathrm{g} / \mathrm{kg}$ LPS where cardiac frequency also decreased. The significant cardiac frequency increase with the high LPS dose could be an explanation for the greater oxygen saturation observed in this group. Therefore, the most important anesthetic parameter to monitor when endotoxemia is present during anesthesia would be oxygen saturation that significantly decreases with LPS, as this could very well be related to decreased cardiac output. ${ }^{27}$ Ketamine is known to increase cardiac frequency, but variable effects have been seen in cardiac output in rats. ${ }^{26}$ Since xylazine causes bradycardia, ${ }^{26}$ the increase in plasmatic concentrations of xylazine with the low and moderate LPS concentrations could be related to the decrease in cardiac frequency.

An increase in alanine aminotransferase is commonly used to indicate hepatic damage in rat experimental models of sepsis. ${ }^{28,29}$ In the current study, blood biochemistry showed no significant effect on hepatic function with LPS even though minor histological lesions were present in all LPS groups, suggesting that sufficient normal hepatic tissue is still present to preserve liver function. Even without lesions, hypoalbuminemia and hypoproteinemia are frequently observed with isoflurane or ketamine-xylazine anesthesia, ${ }^{10,30}$ suggesting an effect on hepatic metabolism. Ketamine is $\mathrm{N}$-demethylated by cytochrome P450 into norketamine. ${ }^{31}$ It has been reported that cytochrome $\mathrm{P} 3 \mathrm{~A} 4$ is principally responsible for this metabolism in humans and cytochrome $\mathrm{P} 3 \mathrm{~A}$ in other mammals. ${ }^{31,32}$ Xylazine is metabolized extensively after intramuscular injection. It has been shown that inhibitors of cytochrome
P3A4, such as chloramphenicol, alters xylazine metabolism. ${ }^{33}$ Pretreatment with liver cytochrome P450 inhibitors cause a prolongation of ketamine-xylazine anesthesia in mice, rats, and chickens. ${ }^{34}$ Animal studies show that LPS causes an important decrease in cytochrome P450 activity, ${ }^{6,7}$ which would increase plasmatic drug concentrations metabolized by this pathway. Furthermore, LPS can cause acute renal insufficiency and indirectly affect renal excretion of drugs. ${ }^{35,36}$ In the current study, blood biochemistry and histopathology showed no significant effects of LPS on renal function and therefore renal metabolism doesn't appear to have been altered. Theoretically, plasmatic concentrations of both drugs following the LPS injection should have increased in comparison with control animals receiving saline. These findings fit very well with the increased plasmatic concentrations and urinary excretion of xylazine, as a decrease in metabolism could occur with endotoxemia. However, they do not explain the decreased or unchanged AUC of ketamine even though urinary excretion increased. The urinary excretion of ketamine (fractional excretion for the $10 \mu \mathrm{g} / \mathrm{kg}$ and $100 \mu \mathrm{g} / \mathrm{kg}$ groups was 0.7 and 2.7 , respectively, greater than the controls) was however much less pronounced than for xylazine (fractional excretion for the $10 \mu \mathrm{g} / \mathrm{kg}$ and $100 \mu \mathrm{g} / \mathrm{kg}$ was 26.8 and 8.5 , respectively, greater than the controls). Here, again, it is suggested that a redistribution of the drugs to tissues, including the brain, may explain a prolonged anesthesia duration. A better understanding of the hepatic and renal excretion of ketamine and xylazine during endotoxemia is also required to properly interpret the results. These changes could be a consequence of systemic inflammation and therefore other inductors of inflammation should also be evaluated.

All albumin plasmatic concentrations were lower after ketamine-xylazine injection; however, the most important decrease was seen with the $100 \mu \mathrm{g} / \mathrm{kg}$ LPS administration. This lower albumin concentration in the high LPS group could cause an increase in the free plasmatic drug fraction for both ketamine and xylazine, and could consequently cause a greater distribution to the central nervous system, which could explain longer anesthesia duration at least for the high LPS dose. Since protein binding of ketamine is low $(50 \%-60 \%),{ }^{26}$ and no data is available for the protein binding of xylazine, ${ }^{26}$ a clear conclusion regarding the effects of hypoalbuminemia in the current experiment is purely speculative.

Plasmatic pharmacokinetic parameters for ketamine cannot explain the difference in anesthesia duration since ketamine AUCs were either unchanged or decreased with 
LPS administration. A decreased AUC was only seen with $10 \mu \mathrm{g} / \mathrm{kg}$ LPS, with a corresponding increase in the plasmatic clearance and a nonsignificant, but nearly doubled, excreted urinary fraction. Pharmacokinetic parameters for xylazine could be associated with the longer anesthesia duration since its AUC increased for both the $10 \mu \mathrm{g} / \mathrm{kg}$ and $100 \mu \mathrm{g} / \mathrm{kg}$ LPS groups. Xylazine AUCs increased and the plasmatic clearances decreased for the $10 \mu \mathrm{g} / \mathrm{kg}$ and $100 \mu \mathrm{g} / \mathrm{kg} \mathrm{LPS}$ groups even though the urinary excreted fractions increased. Xylazine exposure is therefore increased for the high LPS concentrations and this could be associated with longer anesthesia duration. Changes in the blood-brain barrier in the presence of LPS may also be responsible for the longer anesthesia duration. P-glycoprotein is a brain-to-blood efflux system that controls the ability of many drugs and endogenous substances to access the brain. In vitro work has shown that inflammatory states mediated through LPS may stimulate P-glycoprotein activity. ${ }^{37}$ Further studies evaluating the availability of ketamine and xylazine in brain tissue following LPS administration should be conducted to verify this hypothesis.

\section{Conclusion}

LPS has a profound effect on the physiological and pharmacological parameters following an administration of ketamine and xylazine given at an anesthetic dose. Anesthesia duration significantly increased for the moderate and high LPS groups. The most important physiological change that occurred with LPS was a decrease in oxygen saturation, and for blood biochemistry a decrease of serum albumin. Ketamine pharmacokinetics were not affected except for the $10 \mu \mathrm{g} / \mathrm{kg}$ LPS group, where a decrease in $\mathrm{AUC}_{0-\mathrm{t}}$ and half-life and an increase in the clearance were observed. For xylazine, the AUC increased and the clearance decreased for the moderate and high LPS groups. Dose adjustments could be made to modify anesthesia when fever or endotoxemia are present in animals to obtain a more rapid recovery after anesthesia. The results suggest that the xylazine dose could be reduced since its biodistribution appears to increase with moderate and high doses of LPS.

\section{Acknowledgments}

The authors would like to thank Guy Beauchamp, statistician at the Faculty of Veterinary Medicine, for the statistical analyses.

\section{Disclosure}

The authors report no conflicts of interest in this work.

\section{References}

1. Hansen MK, Daniels S, Goehler LE, Gaykema RP, Maier SF, Watkins LR. Subdiaphragmatic vagotomy does not block intraperitoneal lipopolysaccharide-induced fever. Auton Neurosci. 2008;85(1-3):83-87.

2. Cassatella MA, Meda L, Bonora S, Ceska M, Constantin G. Interleukin 10 (IL-10) inhibits the release of proinflammatory cytokines from human polymorphonuclear leukocytes. Evidence for an autocrine role of tumor necrosis factor and IL-1 beta in mediating the production of IL-8 triggered by lipopolysaccharide. J Exp Med. 1993;178(6):2207-2211.

3. Yang KH, Lee MG. Effects of endotoxin derived from Escherichia coli lipopolysaccharide on the pharmacokinetics of drugs. Arch Pharm Res. 2008;31(9):1073-1086.

4. Hewett JA, Roth RA. Hepatic and extrahepatic pathobiology of bacterial lipopolysaccharides. Pharmacol Rev. 1993;45(4):382-411.

5. Hirata K, Kaneko A, Ogawa K, Hayasaka H, Onoe T. Effect of endotoxin on rat liver. Analysis of acid phosphatase isozymes in the liver of normal and endotoxin-treated rats. Lab Invest. 1980;43(2):165-171.

6. Shedlofsky SI, Israel BC, McClain CJ, Hill DB, Blouin RA. Endotoxin administration to humans inhibits hepatic cytochrome P450-mediated drug metabolism. J Clin Invest. 1994;94(6):2209-2214.

7. Ueyama J, Nadai M, Kanazawa H, et al. Endotoxin from various Gram-negative bacteria has differential effects on function of hepatic cytochrome P450 and drug transporters. Eur J Pharmacol. 2005;510(1-2):127-134.

8. Crawford EK, Ensor JE, Kalvakolanu I, Hasday JD. The role of 3' poly(A) tail metabolism in tumor necrosis factor-alpha regulation. J Biol Chem. 1997;272(34):21120-21127.

9. Stokes EL, Flecknell PA, Richardson CA. Reported analgesic and anaesthetic administration to rodents undergoing experimental surgical procedures. Lab Anim. 2009;43(2):149-154.

10. Meyer RE, Fish RE. Pharmacology of injectable anesthetics, sedatives, and tranquilizers. In: Fish RE, Brown MJ, Danneman PJ, Karas AZ, editors. Anesthesia and Analgesia in Laboratory Animals. 2nd ed. San Diego, CA: Academic Press; 2008:27-82.

11. Richardson CA, Flecknell PA. Anaesthesia and post-operative analgesia following experimental surgery in laboratory rodents: are we making progress? Altern Lab Anim. 2005;33(2):119-127.

12. Wixson SK, White WJ, Hughes HC Jr, Lang CM, Marshall WK. A comparison of pentobarbital, fentanyl-droperidol, ketamine-xylazine and ketamine-diazepam anesthesia in adult male rats. Lab Anim Sci. 1987;37(6):726-730.

13. Salonen JS. Chemistry and pharmacokinetics of the alpha2-adrenoreceptor agonist. In: Short CE, Van Poznak A, editors. Animal Pain. New York, NY: Churchill Livingstone; 1992:191-200.

14. Aydin M, Kislal FM, Ayar A, et al. The effects of lipopolysaccharideinduced endogenous hyperthermia and different antipyretic treatment modalities on rat brain. Bratisl Lek Listy. 2011;112(5):227-234.

15. Rummel C, Matsumura K, Luheshi GN. Circulating IL-6 contributes to peripheral LPS-induced mPGES-1 expression in the rat brain. Brain Res Bull. 2011;86(5-6):319-325.

16. Wrotek S, Jedrzejewski T, Potera-Kram E, Kozak W. Antipyretic activity of N-acetylcysteine. J Physiol Pharmacol. 2011;62(6):669-675.

17. Sharp PE, LaRegina MC. Important biological features. In: Sharp PE, LaRegina MC, Suckow MA, editor. The Laboratory Rat. Boca Raton, FL: CRC Press; 1998:14-16.

18. Rowland M, Towzer TN. Clinical Pharmacokinetics: Concepts and Applications. Philadelphia, PA: Lippincott, Williams, and Wilkins; 1995:367-389. Miller JB. Hyperthermia and fever of unknown origin. In: Ettinger SJ, Feldman EC, editors. Textbook of Veterinary Internal Medicine. 7th ed. St Louis, MO: Saunders Elsevier; 2010:41-45.

19. Tolchard S, Burns PA, Nutt DJ, Fitzjohn SM. Hypothermic responses to infection are inhibited by alpha2-adrenoceptor agonists with possible clinical implications. Br J Anaesth. 2009;103(4):554-560.

20. Davies P, Maconochie I. The relationship between body temperature, heart rate and respiratory rate in children. Emerg Med J. 2009;26(9): 641-643. 
21. Allen DG, Dyson DH, Pascoe PJ, O'Grady MR. Evaluation of a xylazine-ketamine hydrochloride combination in the cat. Can J Vet Res. 1986;50(1):23-26.

22. Hart CY, Burnett JC Jr, Redfield MM. Effects of avertin versus xylazineketamine anesthesia on cardiac function in normal mice. Am J Physiol Heart Circ Physiol. 2001;281(5):H1938-H1945.

23. Ilback NG, Stalhandske T. Cardiovascular effects of xylazine recorded with telemetry in the dog. J Vet Med A Physiol Pathol Clin Med. 2003;50(10):479-483.

24. Dittmar MS, Fehm NP, Vatankhah B, Horn M. Ketamine/xylazine anesthesia for radiologic imaging of neurologically impaired rats: dose response, respiratory depression, and management of complications. Comp Med. 2004;54(6):652-655.

25. Fish SH, Brown MJ, Danneman PJ, Karas AZ, editors. Anesthesia and Analgesia of Laboratory Animals. 2nd ed. San Diego, CA: Academic Press; 2008.

26. Rackow EC, Astiz ME, Kim YB, Weil MH. Monophosphoryl lipid A blocks the hemodynamic effects of lethal endotoxemia. J Lab Clin Med. 1989;113(1):112-117.

27. Col R, Durgun Z. Effect of recombinant interleukin-10 on some haematological and biochemical parameters in a rat endotoxaemic model. Acta Vet Hung. 2011;59(2):237-245.

28. Moller S, LaigaardF, Olgaard K, Hemmingsen C. Effect of 1,25-dihydroxyvitamin D3 in experimental sepsis. Int J Med Sci. 2007;4(4):190-195.

29. DeckardtK, Weber I, Kaspers U, Hellwig J, Tennekes H, van Ravenzwaay B The effects of inhalation anaesthetics on common clinical pathology parameters in laboratory rats. Food Chem Toxicol. 2007;45(9): 1709-1718.
30. Hijazi Y, Boulieu R. Contribution of CYP3A4, CYP2B6, and CYP2C9 isoforms to N-demethylation of ketamine in human liver microsomes. Drug Metab Dispos. 2002;30(7):853-858.

31. Capponi L, Schmitz A, Thormann W, Theurillat R, Mevissen M. In vitro evaluation of differences in phase 1 metabolism of ketamine and other analgesics among humans, horses, and dogs. Am J Vet Res. 2009;70(6):777-786.

32. Grubb TL, Muir WW 3rd, Bertone AL, Beluche LA, Garcia-Calderon M. Use of yohimbine to reverse prolonged effects of xylazine hydrochloride in a horse being treated with chloramphenicol. J Am Vet Med Assoc. 1997;210(12):1771-1773.

33. Roder JD, Akkaya R, Amouzadeh HR, Sangiah S, Burrows G, Qualls CW Jr. Effects of hepatic P-450 enzyme inhibitors and inducers on the duration of xylazine + ketamine anesthesia in broiler chickens and mice. Vet Hum Toxicol. 1993;35(2):116-118.

34. Fabre J, Balant L. Renal failure, drug pharmacokinetics and drug action. Clin Pharmacokinet. 1976;1(2):99-120.

35. Hirschberg R, Hofer W, Schaefer K. Endotoxin-induced acute renal failure in mice. Effects of indomethacin and the thromboxane-synthetase antagonist UK 38.485. Res Exp Med (Berl). 1985;185(2):107-113.

36. Salkeni MA, Lynch JL, Otamis-Price T, Banks WA. Lipopolysaccharide impairs blood-brain barrier P-glycoprotein function in mice through prostaglandin- and nitric oxide-independent pathways. J Neuroimmune Pharmacol. 2009;4(2):276-282.
Veterinary Medicine: Research and Reports

\section{Publish your work in this journal}

Veterinary Medicine: Research and Reports is an international, peer-reviewed, open access journal publishing original research, case reports, editorials, reviews and commentaries on all areas of veterinary medicine. The manuscript management system is completely online and includes a very quick and fair peer-review system.

\section{Dovepress}

Visit http://www.dovepress.com/testimonials.php to read real quotes from published authors. 